\title{
DON content in oat grains in Norway related to weather conditions at different growth stages
}

by Hjelkrem, A.R., Torp, T., Brodal, G., Aamot, H.U., Strand, E., Nordskog, B., Dill-Macky, R., Edwards, S.G. and Hofgaard, I.S.

Copyright, Publisher and Additional Information: Publishers version distributed under the terms of the Creative Commons Attribution License:

http://creativecommons.org/licenses/by/4.0/

DOI: 10.1007/s10658-016-1113-5

Harper Adams

University

Hjelkrem, A.R., Torp, T., Brodal, G., Aamot, H.U., Strand, E., Nordskog, B., Dill-Macky, R., Edwards, S.G. and Hofgaard, I.S. 2016. DON content in oat grains in Norway related to weather conditions at different growth stages. European Journal of Plant Pathology. 


\title{
DON content in oat grains in Norway related to weather conditions at different growth stages
}

\author{
Anne-Grete Roer Hjelkrem • Torfinn Torp • Guro Brodal • Heidi Udnes Aamot • \\ Einar Strand • Berit Nordskog • Ruth Dill-Macky • Simon G. Edwards • \\ Ingerd Skow Hofgaard
}

Accepted: 17 November 2016

(C) The Author(s) 2016. This article is published with open access at Springerlink.com

\begin{abstract}
High concentrations of the mycotoxin deoxynivalenol (DON), produced by Fusarium graminearum have occurred frequently in Norwegian oats recently. Early prediction of DON levels is important for farmers, authorities and the Cereal Industry. In this study, the main weather factors influencing mycotoxin accumulation were identified and two models to predict the risk of DON in oat grains in Norway were developed: (1) as a warning system for farmers to decide if and when to treat with fungicide, and (2) for authorities and industry to use at harvest to identify potential food safety problems. Oat grain samples from farmers' fields were collected together with weather data (2004-2013).
\end{abstract}

Electronic supplementary material The online version of this article (doi:10.1007/s10658-016-1113-5) contains supplementary material, which is available to authorized users.

A.-G. R. Hjelkrem $(\bowtie) \cdot$ T. Torp • G. Brodal •

H. U. Aamot • E. Strand • B. Nordskog • I. S. Hofgaard

Norwegian Institute of Bioeconomy Research (NIBIO), Pb 115,

1431 Ås, Norway

e-mail: anne-grete.hjelkrem@nibio.no

E. Strand

Norwegian Agricultural Extension Service, Osloveien 1, 1430 Ås, Norway

R. Dill-Macky

Department of Plant Pathology, University of Minnesota, 495

Borlaug Hall, 1991 Upper Buford Circle, St Paul, MN 55108, USA

S. G. Edwards

Crop and Environment Sciences Department, Harper Adams University, Newport, Shropshire TF10 8NB, UK
A mathematical model was developed and used to estimate phenology windows of growth stages in oats (tillering, flowering etc.). Weather summarisations were then calculated within these windows, and the Spearman rank correlation factor calculated between DONcontamination in oats at harvest and the weather summarisations for each phenological window. DON contamination was most clearly associated with the weather conditions around flowering and close to harvest. Warm, rainy and humid weather during and around flowering increased the risk of DON accumulation in oats, as did dry periods during germination/seedling growth and tillering. Prior to harvest, warm and humid weather conditions followed by cool and dry conditions were associated with a decreased risk of DON accumulation. A prediction model, including only pre-flowering weather conditions, adequately forecasted risk of DON contamination in oat, and can aid in decisions about fungicide treatments.

Keywords Deoxynivalenol Phenological development $\cdot$ Spearman rank correlation factor

\section{Introduction}

Fusarium head blight (FHB) is a widely distributed cereal disease caused by various Fusarium species. As many of these fungi can produce mycotoxins, FHB may result in mycotoxin accumulation in cereal grains. High concentrations of the mycotoxin deoxynivalenol (DON), produced by Fusarium graminearum, have 
frequently occurred in Norwegian oat grains in recent years (Norwegian Scientific Commitee for Food Safety 2013; Hofgaard et al. 2016a), and the food and feed quality of the grain is accordingly reduced. The European Commission has set guidance limits for DON contamination in animal feed (EC 576/2006) and legislative limits for human consumption (EC 1881/2006).

Early prediction of mycotoxin levels would be an important tool for farmers to optimize management strategies, and for the authorities and industry to limit potential food and feed safety problems. By identifying the main factors that influence mycotoxin accumulation and their interactions, a better understanding of the accumulation of this mycotoxin will be achieved and a prediction model can be developed.

Weather is the most important factor related to mycotoxin accumulation in harvested grain (Hooker et al. 2002; Gourdain et al. 2011; Landschoot et al. 2012b). The relationship between weather variables, especially during flowering and grain maturation, and accumulation of DON is widely documented in wheat (Hooker et al. 2002; Klem et al. 2007; Franz et al. 2009; Landschoot et al. 2012b; Andersen et al. 2015). For oat, the relationship is not well explored, except for the study by Lindblad et al. (2011), who stated that very little of the variation in DON could be explained by weather conditions. Morphological and developmental differences between cereal species, such as a longer flowering period for oat (Rajala and Peltonen-Sainio 2011) compared to wheat, may result in differences in the associations between weather and DON accumulation for the different cereal species. Developing prediction models for DON accumulation in oat grains might be more challenging than in wheat, among other things due to the longer flowering period. In order to establish prediction models for DON levels in oat grains, more information on the relationship between weather conditions and DON development is needed.

The mycotoxin content in grain at harvest is variable and depends largely on the interaction of plant growth stage and weather (Hooker et al. 2002; Culler et al. 2007; Klem et al. 2007; Cowger et al. 2009; Franz et al. 2009; Gourdain et al. 2011; Landschoot et al. 2012b; Xu et al. 2013, 2014). Weather summarisations are therefore frequently calculated within different temporal time intervals (Coakley et al. 1982), fixed for the number of days (7 days, 10 days etc.), and correlations with mycotoxin content in harvested grain are calculated individually for each time window. The start of a temporal time window is usually fixed at a specific date (Kriss et al. 2010; Xu et al. 2014), or at an observed plant growth stage (Kriss et al. 2012). For FHB and mycotoxins, weather conditions have been successfully related to time intervals at defined plant growth stages, especially around flowering (Hooker et al. 2002; Gourdain et al. 2011; Xu et al. 2014). Linking the time windows directly to plant growth stages, instead of the calendar, would be more effective since the date of sowing and harvest differ between years and fields (Xu et al. 2014). One drawback, which prevents use of growth stages instead of the date is that the growth stages are rarely recorded in farmers' fields.

The main objective of this study was to identify possible associations between weather conditions at specific oat growth stages and the content of DON in harvested oat grains. The study was performed in three parts. In the first part, a mathematical model (oat phenology model) based upon weather data and sowing date connected to 399 observations of oats collected from experimental fields was developed and used to estimate intervals of growth stages (phenology windows) such as tillering, heading/flowering and grain ripening. In the second part, the oat phenology model was used to estimate phenology windows for 258 oat grain samples from farmer fields, and the Spearman rank correlations between the weather within each window and the DON content the harvested oats were calculated. Associations between weather factors and DON development were identified. In the third part, the most important weather variables were used in the development of two empirical models to predict risk of DON accumulation: (1) mid-season as a warning system for farmers to decide if and when to treat with fungicide against FHB, and (2) end-of-season for the authorities and industry to identify grain lots with potential food safety problems.

\section{Materials and methods}

Part 1: oat phenology model

\section{Field data}

Phenological data on oat growth stages were obtained from several field experiments hosted by the Nordic Field Trial System, where the BBCH scale was used to define plant growth stages (GS) (Lancashire et al. 1991). 
The data were collected at five different sites in Norway (west, east and central regions), between 2006 and 2013 and include seven oat varieties (Belinda, Gere, Haga, Hurdal, Odal, Ringsaker and Scorpion). In addition to GS, variety and sowing date were also recorded for all sites. The final data set consisted of 399 observations, recorded between GS 11 and GS 99, with the majority of observations at GS $59(38 \%)$ and at GS 87 (31\%). Almost half the observations (43\%) were on late maturing oat varieties (Belinda, Odal and Scorpion) while the remaining observations were on varieties defined as early maturing (Haga, Ringsaker, Hurdal and Gere). Approximately five to six days separates the group of early and the group of late maturing varieties in growth time from sowing and until dough development (Åssveen et al. 2015).

\section{Weather and environmental data}

Weather data were collected from on-site weather stations provided by Agrometeorology Norway (2016). Daily and hourly weather records of air temperature $2 \mathrm{~m}$ above ground level $\left(\mathrm{T} ;{ }^{\circ} \mathrm{C}\right)$, soil temperature at $0.1 \mathrm{~m}$ depth $\left(\mathrm{TS} ;{ }^{\circ} \mathrm{C}\right)$ and precipitation $(\mathrm{P} ; \mathrm{mm})$ were recorded.

Day length and photoperiod were estimated for the locations each year. Day length $(\lambda ; \mathrm{h})$ was estimated based on the latitude of the weather stations according to Olseth and Skartveit (1985). Photoperiod (Ph; h), defined as the number of daylight hours best suited to the growth and maturation of an organism, was calculated according to Olesen et al. (2012). The degree-day accumulation was calculated by daily air temperatures from sowing onwards with a base air temperature of $0{ }^{\circ} \mathrm{C}$, although different adjustments were tested (Table 1).

\section{The oat phenology model}

Ten simple models were developed and tested in order to estimate phenological development of oat growth (Table 1). The proposed models were based on air temperature, soil temperature, precipitation, photoperiodic time and day length, which are easily available variables assumed to be of importance for plant development (Davidson and Campbell 1983; Shaykewich 1995; Saarikko and Carter 1996; Wang and Engel 1998; Sonego et al. 2000; McMaster et al. 2008; Rajala and Peltonen-Sainio 2011; Olesen et al. 2012; Siebert and Ewert 2012). The Gompertz growth function
Table 1 Mathematical models (1-10) used to calculate an adjusted degree-day accumulation and root mean square error of prediction after cross validation

\begin{tabular}{lll}
\hline Model & Adjusted degree-day & Root mean square error $\mathrm{a}$ \\
\hline 1 & $D D_{i}=\sum_{i}\left(T_{i}\right)_{+\mathrm{b}}$ & $4.6244(1.1822)$ \\
2 & $D D_{i}=\sum_{i}\left(T_{i}-5\right)_{+\mathrm{b}}$ & $5.2451(1.8731)$ \\
3 & $D D_{i}=\sum_{i}\left(T_{i} \cdot r_{i}\right)_{\mathrm{c}}$ & $5.0545(1.2016)$ \\
4 & $D D_{i}=\sum_{i} \lambda_{i} / 24 \cdot\left(T_{i}\right)_{+\mathrm{b}}$ & $4.6748(1.2999)$ \\
5 & $D D_{i}=\sum_{i} \lambda_{i} / 24 \cdot\left(T_{i}-5\right)_{+\mathrm{b}}$ & $5.3879(1.9332)$ \\
6 & $D D_{i}=\sum_{i} P h_{i} \cdot\left(T_{i}\right)_{+\mathrm{b}}$ & $4.7835(1.3943)$ \\
7 & $D D_{i}=\sum_{i} P h_{i} \cdot\left(T_{i}-5\right)_{+} \mathrm{b}$ & $5.5211(1.9775)$ \\
8 & $D D_{i}=\sum_{i}\left(T S_{i}\right)_{+\mathrm{b}}$ & $5.2845(1.7195)$ \\
9 & $D D_{i}=\sum_{i}\left(T S_{i}-5\right)_{+\mathrm{b}}$ & $5.9016(2.2887)$ \\
10 & $D D_{i}=\sum_{i} R R_{i} \cdot\left(T_{i}\right)_{+\mathrm{b}, \mathrm{d}}$ & $4.6425(1.0181)$ \\
\hline
\end{tabular}

The abbreviations of the weather factors are described in the Materials and methods section

a The values are given as mean value and standard deviation (listed in parentheses) over the eight test data sets used in cross validation b "+" indicates that only the positive outcome of the expression in parentheses is used

c $r_{i}=\left(\frac{T_{\max }-T_{i}}{T_{\max }-T_{\text {opt }}}\right) \cdot\left(\frac{T_{i}-T_{\min }}{T_{\text {opt }}-T_{\min }}\right)^{\left(\frac{T_{\text {opt }}-T_{\min }}{T_{\max }-T_{\min }}\right)}$, where $T_{\max }, T_{\min }$ and $T_{o p t}$ are parameters for the cardinal temperatures (Yan and Hunt 1999) ${ }_{\mathrm{d}} R R_{i}=1$ if $P_{i}<10 \mathrm{~mm}$ and $\mathrm{RR}_{\mathrm{i}}=0$ if $P_{i} \geq 10 \mathrm{~mm}\left(P_{i}=\right.$ Precipitation at day $i$ )

(Batschelet 1976), which is a sigmoid function with asymmetrical growth (Eq. 1), was used as the base function for all proposed model versions.

$G S_{i}=99 e^{\alpha e^{\beta D D_{i}}}$

The model output, $G S_{i}$ is the estimated phenological growth stage of oat at day $i, D D_{i}$ is the adjusted degreeday accumulation at day $i, 99$ is the asymptote fixed at the maximum GS value according to the $\mathrm{BBCH}$ scale and both $\alpha$ and $\beta$ are unknown model parameters (Table 2). The ten different models differed in the way of including observed air temperature, soil temperature, precipitation, day length or photoperiodic time to calculate an adjusted degree-day accumulation (Table 1).

The degree-day accumulations were calculated from sowing day and onwards. In the simplest models, a degree-day accumulation with a base air temperature of $0{ }^{\circ} \mathrm{C}$ (Model 1) or a base air temperature of $5{ }^{\circ} \mathrm{C}$ (Model 2) was used. A more complex degree-day adjustment was tested in Model 3, where the temperatures were weighted differently based on a weighting function 
for the daily rate of plant growth based on the three cardinal temperatures $\left(T_{\max }, T_{\min }\right.$ and $T_{o p t}$ ) (Yan and Hunt 1999). In Model 4 and Model 5, base temperatures of $0{ }^{\circ} \mathrm{C}$ and $5{ }^{\circ} \mathrm{C}$ were used, respectively, in addition to a weighting function calculated by the day length $\left(\lambda_{i}\right)$ divided by 24 h. Similarly, Model 6 and Model 7 included respectively a base temperature of $0{ }^{\circ} \mathrm{C}$ and $5{ }^{\circ} \mathrm{C}$ in addition to a weighting function calculated from the estimated photoperiod $\left(P h_{i}\right)$. Model 8 and Model 9 were equivalent to the two first models, except using soil temperatures instead of air temperatures. The last proposed model, Model 10, used a base temperature of $0{ }^{\circ} \mathrm{C}$ and included only temperatures on days with less than $10 \mathrm{~mm}$ precipitation.

Values for the model parameters (Table 2) were estimated by Bayesian calibration (Robert and Casella 1999). According to Bayesian learning, posterior parameter distributions were calculated as a combination of the original parameter uncertainty (prior knowledge) and the new incorporated information through the conditional probability distribution of the collected data (likelihood function). The prior probability distributions were described by wide uniform independent distributions (Table 2), while the likelihood function, after some simplifications, were determined by the distribution of model errors (Rougier 2007). The calculations were done using the Markov chain Monte Carlo (MCMC) algorithm Random walk Metropolis (Robert and Casella 1999).

Cross validation (Hastie et al. 2001) is a standard method that uses the available data in an optimal way. When the amount of data is limited, the characteristic of the test data may differ from the training data and cause bias in the model assessment. In order to avoid bias and provide a reliable measure of the models' predictive quality, the data was split into eight different training and test sets according to the cross-year technique introduced by Landschoot et al. (2012a). Root mean square error of predictions were calculated using the maximum posterior parameter estimate, which is the parameter set that had the highest joint posterior probability and given as mean values and standard deviations over the eight splits of data. The model version with the lowest root mean square error of prediction over the cross validation splits was selected as the best model for oat growth prediction and used in the subsequent studies.

Part 2: association between DON content and weather conditions

\section{Oat samples}

Representative oat grain samples, of about $1 \mathrm{~kg}$, were randomly collected at farms or at delivery points of oats from farmers' fields across Norway (south, east and central regions) from 2004 to 2013. Samples were processed and stored according to Aamot et al. (2012), except for samples collected after 2009 that were divided into sub-samples of $200 \mathrm{~g}$ and ground using a ZM 200 mill (Retsch, Haan, Germany) with a 1-mm sieve. Grain samples from fields treated with fungicides against Fusarium were excluded in this study. The final dataset consisted of samples from 258 oat fields, with the majority from 2007 (19\%) and 2008 (19\%). Close to $50 \%$ of the samples were collected in the Solør-Odal region, where oat is an important cereal crop.

\section{Mycotoxin analysis}

Of the 258 oat grain samples analysed for DON contamination in this study, 175 samples were analysed by a LC-MS/MS method with a limit of quantification (LOQ) of $100 \mu \mathrm{g} \mathrm{kg}^{-1}$ (Kokkonen and Jestoi 2009) and 24 samples were analysed with a LC-MS/MS method with a LOQ of $100 \mu \mathrm{g} \mathrm{kg}^{-1}$ (NIBIO, unpublished). The remaining 59 samples were analysed by an ELISA method (AgraQuant ${ }^{\circ}$ Deoxynivalenol Assay, Romer Labs®, Tulln, Austria) with LOQ of $250 \mu \mathrm{g} \mathrm{kg}^{-1}$. For
Table 2 Description of the parameters in the proposed oat phenology models, with minimum and maximum values used in the uniform prior distributions

\begin{tabular}{lllll}
\hline Parameter & Unit & Description & Minimum & Maximum \\
\hline$\alpha$ & - & Sets the y displacement & -20 & -0.05 \\
$\beta$ & - & Sets the growth rate & -0.5 & -0.00005 \\
$T_{\min }$ & ${ }^{\circ} \mathrm{C}$ & Minimum air temperature for oat growth & -2 & 2 \\
$T_{\max }$ & ${ }^{\circ} \mathrm{C}$ & Maximum air temperature for oat growth & 23 & 33 \\
$T_{\text {opt }}$ & ${ }^{\circ} \mathrm{C}$ & Optimum air temperature for oat growth & 16 & 22 \\
\hline
\end{tabular}


samples with a DON content below the LOQ, a value of LOQ/6 (European Commission 2003) was used. The ELISA analysis was performed according to the manufacturer's instructions, except the sample extraction, where $25 \mathrm{ml}$ of distilled water was added to $5 \mathrm{~g}$ of ground sample, followed by vigorous shaking for $3 \mathrm{~min}$. The mixture was centrifuged for $1 \mathrm{~min}$ at $1811 \times \mathrm{g}$, and the supernatant was diluted 1:4 with distilled water.

\section{Weather and environmental data}

Weather data were collected as previously described in Part 1, using daily and hourly values for air temperature $\left(\mathrm{T} ;{ }^{\circ} \mathrm{C}\right)$, precipitation $(\mathrm{P} ; \mathrm{mm})$ and relative humidity (RH; \%). For each grain sample, data were collected from the nearest weather station. Altogether, data from 24 different weather stations were used. Only samples from farms within a distance of $20 \mathrm{~km}$ (mean distance of $7.6 \mathrm{~km}$ ) from a weather station were included in the analysis.

Vapour pressure deficit (vpd; $\mathrm{kPa}$ ) is defined as the difference between the amount of moisture in the air and the moisture the air can hold when saturated. Saturated vapour pressures were estimated from measured air temperature according to Goff and Gratch (1946). The actual vapour pressure was derived from the estimated saturated vapour pressure and the measured relative humidity (Perry and Green 1997). At an air temperature of $15^{\circ} \mathrm{C}$, a relative humidity of $80 \%$ gives a vpd equal to $0.34 \mathrm{kPa}$, while $90 \% \mathrm{RH}$ gives a vpd of $0.17 \mathrm{kPa}$ and $70 \% \mathrm{RH}$ gives a vpd of $0.51 \mathrm{kPa}$.

\section{Data analysis}

Dates for all growth stages from sowing to harvest were estimated for each grain sample by using the phenology model that gave the best fit after cross validation. For the further analysis, the dataset from each grain sample was separated into ten intervals reflecting the different plant developmental stages, subsequently referred to as phenology windows. The phenology windows were selected in order to include growth stages that correspond to germination/seedling growth, tillering, stem elongation, booting, inflorescence emergence, heading/flowering, milk development, late milk, dough development and ripening (Table 3). For each grain sample, data for air temperature, precipitation and relative humidity, recorded at the nearest weather station, was summarised within each predicted phenological window. Possible associations between the mycotoxin content of DON in harvested oats and the weather summarisations within each phenological window were calculated for the whole data set (258 grain samples) using the Spearman rank correlation coefficient (Spearman 2010). This coefficient measures the association between two ranked variables, and it was used due to the non-normal data and the strong outliers consisting of some high DON values.

\section{Part 3: prediction model for risk of DON}

Discriminant analysis with stepwise selection and leave one out cross validation was used in order to develop two models to predict the risk of DON in harvested oats (according to human consumption), one mid-season model as part of a warning system for farmers to decide if and when to treat with fungicide in the growing season and the other model to be used at the end of the season by authorities and industry personnel to identify grain lots with potential food safety problems. A rigorous threshold value of $1000 \mu \mathrm{g} \mathrm{kg}^{-1}$ was used (the legislative limit for human consumption is $1750 \mu \mathrm{g} \mathrm{kg}^{-1}$ ). Since a fungicide must be applied during flowering, the first model was constructed using only weather observations from sowing to inflorescence emergence while the other model included weather observations from sowing to harvest. All the weather summarisations with a significant $(p<0.05)$ correlation to DON content at harvest were included in model development (Table S1). As the stepwise selection procedure often are distorted by multicollinearity (Montgomery et al. 2001), the correlations between all significant weather summarisations were calculated, and for all weather summarisations with higher correlations to each other than 0.9 , only the weather summarisation with highest correlation to DON content at harvest was retained [Table 3].

\section{Statistical methods}

SAS 9.4 was used for the discriminant analysis with the functions stepdisc and discrim, while all other calculations were performed using MATLAB (R2016b). The corr function with type Spearman, was used to calculate the Spearman rank correlation coefficient. All other calculations performed in this study were written in script files. 
Table 3 The estimated degree-days from sowing for the start and end of growth stage periods and the average number of days calculated for each phenological growth stage period in oats in Norway according to Oat Phenological Model 1

\begin{tabular}{|c|c|c|c|c|}
\hline Growth Stage (GS) & $\begin{array}{l}\text { Phenological } \\
\text { growth stage period }\end{array}$ & $\begin{array}{l}\mathrm{DD}_{\mathrm{b}} \text { from sowing to start } \\
\text { of GS period }\end{array}$ & $\begin{array}{l}\mathrm{DD}_{\mathrm{b}} \text { from sowing to end } \\
\text { of GS period }\end{array}$ & Number of days $\mathrm{s}_{\mathrm{c}}$ \\
\hline$[0,20$ & Germination/ seedling growth & 0 & 221 & $19.6(3.4)$ \\
\hline$[20,30$ & Tillering & 221 & 359 & $9.7(2.4)$ \\
\hline$[30,40$ & Stem elongation & 359 & 489 & $7.9(1.6)$ \\
\hline$[40,50$ & Booting & 489 & 622 & $8.0(1.3)$ \\
\hline$[50,55$ & Inflorescence emergence & 622 & 693 & $3.7(0.7)$ \\
\hline$[55,70$ & Heading/flowering & 693 & 942 & $14.6(1.6)$ \\
\hline$[70,75$ & Milk development & 942 & 1046 & $6.6(0.8)$ \\
\hline$[75,80$ & Late milk & 1046 & 1171 & $6.6(1.0)$ \\
\hline$[80,90$ & Dough development & 1171 & 1550 & $23.6(3.3)$ \\
\hline$[90,95$ & Ripening & 1550 & 1945 & $11.4(7.8)$ \\
\hline
\end{tabular}

Oat Phenology Model 1 was developed from growth stage observations from 258 oat fields and connected weather data a BBCH scale (Lancashire et al. 1991)

b Degree-day accumulation (DD) with base air temperature of $0{ }^{\circ} \mathrm{C}$

c The mean number of days calculated by the Oat Phenological Model 1 for each phenological growth stage period. The standard deviation is listed in parentheses

\section{Results}

This study was performed in three parts. In Part 1 a simple mathematical model was constructed to predict the phenological development of oats based on weather data, in Part 2 weather conditions during plant development, that were significantly associated with DON accumulation in grains, were identified, while in Part 3 mathematical models to predict DON accumulation in oat grains were developed.

\section{Part 1: oat phenology model}

The ten proposed models (Table 1) for prediction of oat growth stages were calibrated and tested for each of the eight splits of the observed data, according to the crossyear validation technique (Landschoot et al. 2012a). Bayesian calibration was used (Robert and Casella 1999), and maximum posterior point estimates of the parameter vectors were found. Root mean square errors of prediction were calculated following cross validation (Table 1).

According to the error term, root mean square error of prediction, Model 1, which was the simplest proposed model version with a degree-day accumulation using a base air temperature of $0{ }^{\circ} \mathrm{C}$, was selected as the most suitable model, by having the lowest prediction error. Out of the 399 observations of phenological oat growth stages, 20 observations (5\%) were estimated to occur in an earlier phenological window, whereas 19 (5\%) were estimated to occur at a later growth stage window than actually observed. Model 1 was recalibrated using all collected data, and maximum posterior point values estimated for $\alpha$ and $\beta$ were $\alpha=$ -2.5565 and $\beta=-0.0021$. This fitted model will in the following be referred to as 'Oat Phenological Model 1'.

The observed oat growth stages (GS) developed with the number of days from sowing (Fig. 1a), but during the two most studied growth stages, GS 59 (38\% of the observations) and GS 87 (31\% of the observations), wide variation in the number of days from sowing to the specific GS was observed. Similar variation was also found when considering the varieties separately and no significant difference in phenological growth rate was found between the varieties in this study. Growth stage 59 occurred between 53 and 82 days after sowing, with a relative standard deviation of $10.5 \%$, while GS 87 occurred between 81 and 119 days after sowing with a relative standard deviation of $9.7 \%$. The resulting Oat Phenological Model 1 is plotted together with the field data of observed oat growth stages in Fig. 1b, and a smaller variation in degree days was detected for growth stages GS 59 and GS 87. In this model GS 59 was observed between 647 and 894 degree-days after 
a

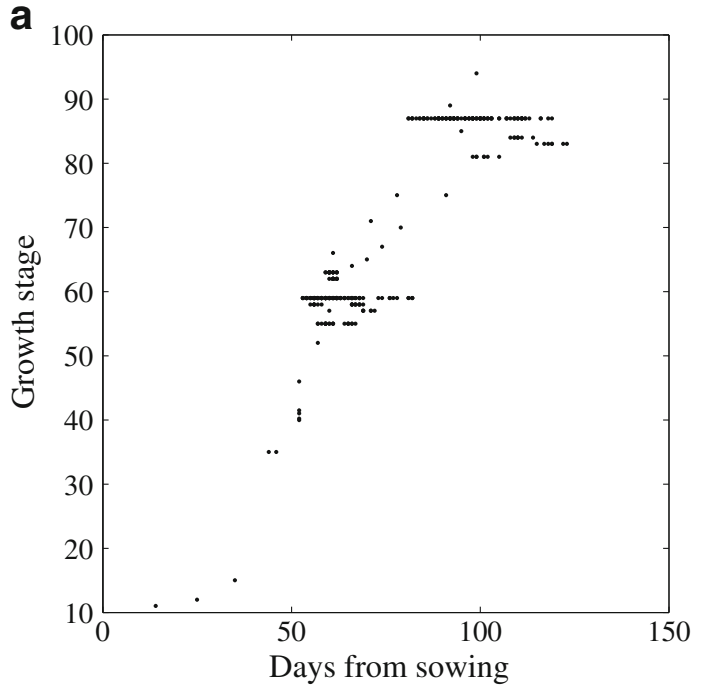

b

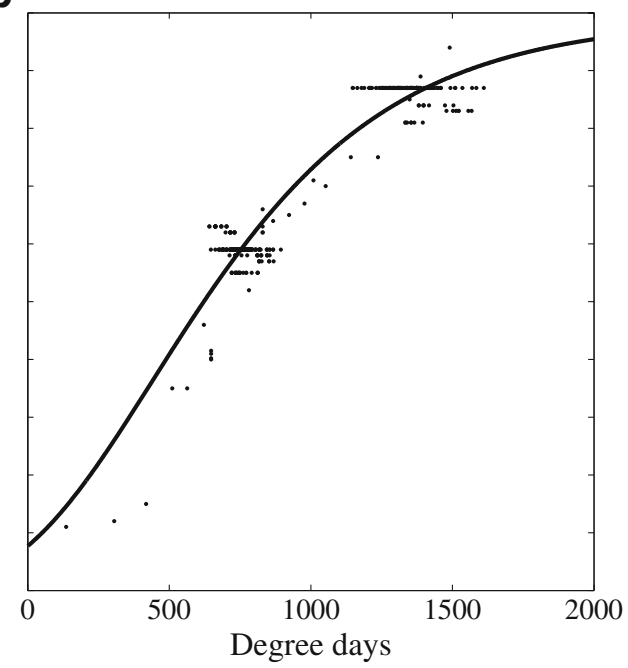

Fig. 1 Phenology development (growth stage) measurements in oats from Norwegian fields, plotted as a function of (a) number of days from sowing; (b) degree-days from sowing with a base temperature of $0{ }^{\circ} \mathrm{C}$. The lines indicate the mathematical oat phenology model

sowing, with a relative standard deviation of $5.8 \%$, while GS 87 was observed between 1148 and 1611 degree-days after sowing with a relative standard deviation of $7.0 \%$.

Part 2: association between DON content and weather conditions

Among the 258 samples analysed for mycotoxin contamination, the amount of DON varied from a maximum of $22,000 \mu \mathrm{g} \mathrm{kg}^{-1}$ to below the levels of detection (LOD). A mean DON value of $1328 \mu \mathrm{g} \mathrm{kg}^{-1}$ and a standard deviation of $2438 \mu \mathrm{g} \mathrm{kg}^{-1}$ was estimated. Thirty-one percent of the samples contained DON levels below the LOQ, while $22 \%$ of the samples contained DON levels above the legislated limits set for unprocessed oats intended for human consumption $\left(1750 \mu \mathrm{g} \mathrm{kg}^{-1}\right)$ and $3 \%$ exceeded the limits set for animal feed $\left(8000 \mu \mathrm{g} \mathrm{kg}^{-1}\right)$.

For all the 258 oat fields, phenological crop development was estimated using air temperatures from the nearest weather station for input to the Oat Phenological Model 1. The predicted growth stages were then grouped into ten phenological windows, such as tillering, heading/flowering and ripening (Table 3). Based on the calculations from Oat Phenological Model 1 using the whole data set of 258 oat grain fields, heading/ flowering was generally estimated to start 7 weeks (50 days, 692 degree-days) from sowing and to last for about two weeks (15 days, 249 degree-days). The ripening phase was estimated to start 15 weeks (102 days, 1550 degree-days) from sowing and to last for almost two weeks (11 days, 395 degree-days). The whole life cycle from sowing to the end of ripening was estimated to last for 16 weeks (113 days, 1945 degreedays).

A total of 90 weather factors, based on air temperature, rainfall and relative humidity were summarised within each of the estimated phenology windows for all oat fields. The weather factors used are given in the $e$ Xtra (Table S1), and were mainly selected based upon literature surveys on factors influencing Fusarium development or mycotoxin accumulation in wheat grains (Kriss et al. 2010; Xu et al. 2013). Table 4 presents the minimum, maximum and mean air temperatures within each of the ten phenological windows across the Norwegian oat fields examined.

Within each of the ten phenological windows, the Spearman rank correlation factor was calculated for the association between DON content in harvested oat grains and each of the 90 different weather factors. Nearly $80 \%$ of the significant $(p<0.05)$ correlations between the mycotoxin content of DON in harvested oats and the weather summarizations during the phenology windows were found in the period from inflorescence emergence onwards. The highest correlations $(r>0.4)$ were detected during dough development and ripening. A few correlation coefficients higher than 0.2 , were found during germination/seedling growth and tillering, while no such high correlations were detected 
during stem elongation and booting. Only correlations significant at the 5\% level are presented in the text, though all calculated correlations are given in the $e$-Xtra (Table S1).

The relationships between DON contamination in oat grains and mean daily air temperature within the phenology windows of selected oat growth stages are given in Fig. 2a. The DON content was positively correlated with mean daily air temperature during early growth stages, which was strengthened while considering the mean daily number of hours with $T \geq 10{ }^{\circ} \mathrm{C}$, during germination/seedling growth $(r=0.16, p=0.010)$ and tillering $(r=0.20, p=0.001)$. By contrast, all significant correlations between the DON content and mean daily air temperature from heading/flowering and onwards were negative, with the highest values observed during dough development $(r=-0.42, p<0.001)$ and ripening $(r=-0.42, p<0.001)$.

The correlations between DON contamination in oat grains and mean daily precipitation within the phenology windows are given in Fig. 2b. DON content was negatively correlated with the mean daily precipitation during germination/seedling growth $(r=-0.15$, $p=0.017$ ), while no significant correlation was detected from tillering to booting (Fig. 2b). A positive correlation was detected between DON content and mean daily precipitation from inflorescence emergence to milk development, with the highest value during heading/ flowering ( $r=0.36, p<0.001)$. When considering the relationship between DON content at harvest and the mean daily number of hours with precipitation, a positive and significant correlation appeared during dough development ( $r=0.15, p=0.015$ ). No correlation was detected between DON content and mean daily precipitation during dough development, while a negative correlation was found during ripening $(r=-0.20$, $p=0.003$ ).

When calculating the effect of relative humidity at earlier growth stages, a small but significant negative association was found between DON concentration in harvested oats and mean daily relative humidity during tillering ( $r=-0.14, p=0.023)$ (Fig. 2c). Positive correlations were found between DON content in harvested oats and mean daily relative humidity from inflorescence emergence to the end of milk development, with the highest values evident during heading/flowering $(r=0.36, p<0.001)$ (Fig. 2c). The correlation during heading/flowering increased when considering the mean daily number of hours with $\mathrm{RH}>70 \%(r=0.39$, $p<0.001)$. During dough development a positive correlation $(r=0.23, p<0.001)$ was detected between DON content at harvest and mean daily relative humidity (Fig. 2c), while no effect was detected during late milk or ripening.

The association between DON and different combinations of air temperature and precipitation $(P>0.2 \mathrm{~mm})$ during plant development were also calculated (Fig. 2d, e). The DON content was not influenced by high $\left(T \geq 15^{\circ} \mathrm{C}\right)$ air temperatures and precipitation (Fig. 2d) during earlier phenological phases, whereas the combination of low air temperatures $\left(T<10{ }^{\circ} \mathrm{C}\right)$ and precipitation during germination/ seedling growth was associated with reduced DON contamination $(r=-0.18, p=0.004)$. A positive correlation was detected between DON content in harvested grain and daily number of hours with $T \geq 15^{\circ} \mathrm{C}$ in combination with precipitation $(P>0.2 \mathrm{~mm})$ in the period from booting to the end of milk development, with the highest value observed during heading/ flowering $(r=0.35, p<0.001)$. The correlation during heading/flowering disappeared when low or high air temperatures $\left(T<10{ }^{\circ} \mathrm{C}\right.$ or $\left.T \geq 20^{\circ} \mathrm{C}\right)$ were combined with precipitation. No significant correlations between DON content and the daily number of hours with precipitation at $T \geq 15^{\circ} \mathrm{C}$ were detected at the later phenological phases (late milk and dough development), while a high negative correlation appeared during ripening $(r=-0.36, p<0.001)$. Positive correlations were evident between DON contamination and low air temperature $\left(T<12{ }^{\circ} \mathrm{C}\right)$ in combination with precipitation during dough development $(r=0.22, p<0.001)$ and ripening $(r=0.33, p<0.001)$.

Significant positive correlations appeared during germination/seedling growth $(r=0.14, p=0.023)$ and tillering ( $r=0.15, p=0.014)$ when considering the relationship between DON content at harvest and the daily number of hours with $T \geq 15^{\circ} \mathrm{C}$ combined with a lack of precipitation during these phenology windows. By contrast, DON content was negatively associated with the number of hours daily with $T \geq 15^{\circ} \mathrm{C}$ combined with no precipitation $(P \leq 0.2 \mathrm{~mm})$ (Fig. 2e) from heading/flowering onwards, with the highest value observed during ripening $(r=-0.39, p<0.001)$. The correlation during ripening increased $(r=-0.43$, $p<0.001)$ when considering a lower air temperature threshold $\left(T \geq 12^{\circ} \mathrm{C}\right)$ combined with no precipitation.

The relationship between DON contamination in harvested oats and the daily number of hours with moist 
Table 4 Mean, standard deviation (SD), minimum and maximum air temperatures (T) during the estimated phenological stages for 258 oat fields in Norway

\begin{tabular}{llllllllll}
$\begin{array}{l}\text { Germination/ } \\
\text { seedling } \\
\text { growth }\end{array}$ & Tillering & $\begin{array}{l}\text { Stem } \\
\text { elongation }\end{array}$ & Booting & $\begin{array}{l}\text { Inflorescence } \\
\text { emergence }\end{array}$ & $\begin{array}{l}\text { Heading/ } \\
\text { flowering }\end{array}$ & $\begin{array}{l}\text { Milk } \\
\text { development }\end{array}$ & $\begin{array}{l}\text { Late } \\
\text { milk }\end{array}$ & $\begin{array}{l}\text { Dough } \\
\text { development }\end{array}$ & Ripening \\
\hline 10.7 & 13.5 & 14.9 & 15.2 & 15.4 & 16.0 & 16.0 & 16.8 & 15.5 & 13.4 \\
1.8 & 3.1 & 2.6 & 2.3 & 2.5 & 1.6 & 1.6 & 2.3 & 1.9 & 2.5 \\
6.4 & 8.4 & 10.5 & 11.5 & 11.1 & 12.5 & 12.9 & 13.1 & 10.1 & 5.9 \\
16.3 & 20.6 & 21.0 & 22.0 & 22.2 & 20.6 & 20.9 & 21.7 & 19.6 & 18.0 \\
\hline
\end{tabular}

weather (vpd $\leq 0.34 \mathrm{kPa})$ is given in Fig. $2 \mathrm{f}$. A weak, but significant negative association was observed between DON content and daily number of hours with moist weather during germination/seedling growth $(r=-0.13, p=0.035)$. On the contrary, positive correlations were found from inflorescence emergence and
Fig. 2 The Spearman rank correlation factors, calculated between DON $(\mu \mathrm{g} / \mathrm{kg})$ contamination in harvested oats and weather conditons, during estimated time-periods (phenology windows) of plant growth stages (BBCH scale). Asterisks indicate that the correlation is significant at the $10 \%$ level (*) or the $5 \%$ level (**)

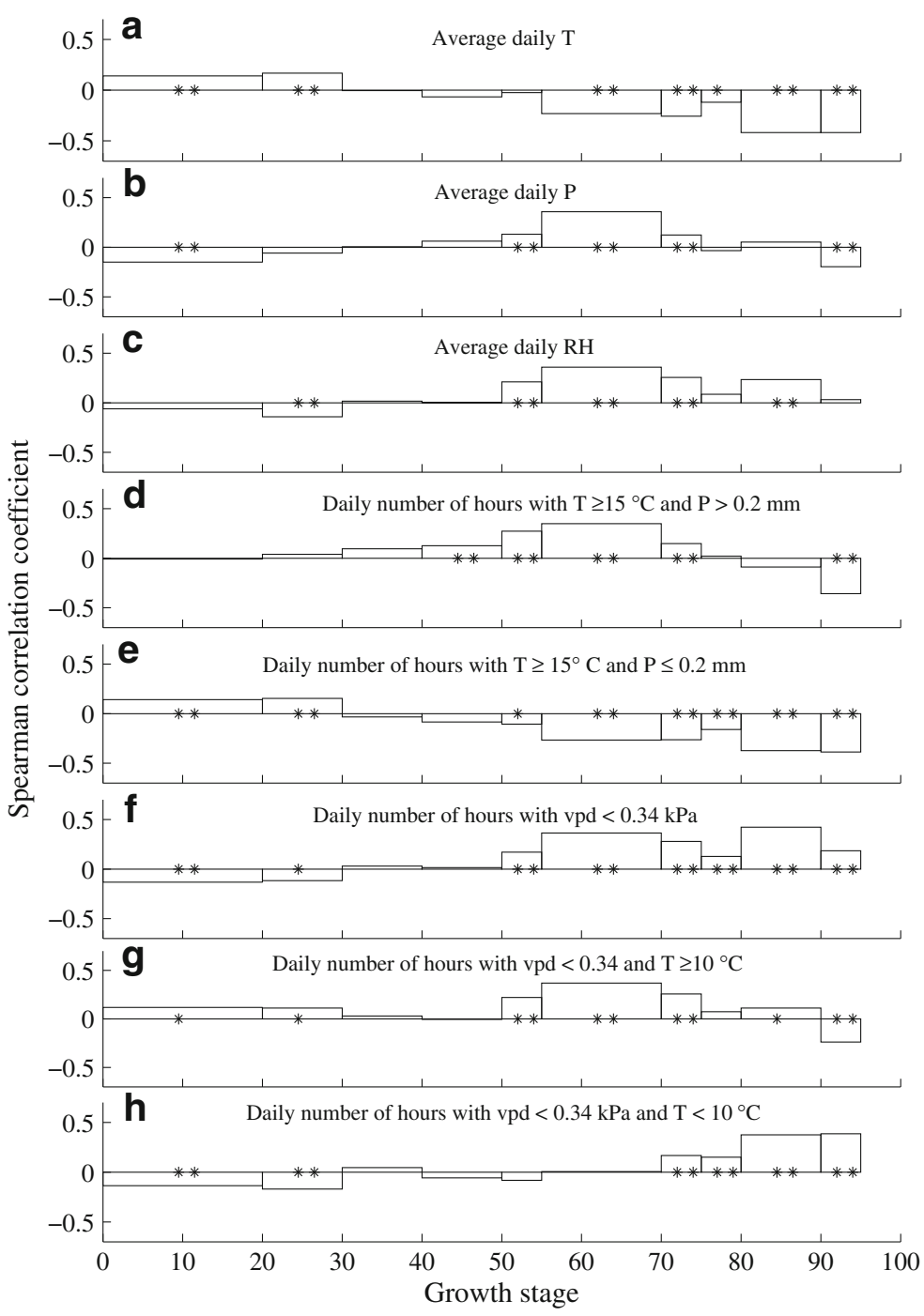


onwards, with highest values during heading/flowering $(r=0.36, p<0.001)$ and dough development $(r=0.42$, $p<0.001)$.

The effect of a combination of moist and moderate to warm weather is given in Fig. $2 \mathrm{~g}$. A weaker positive correlation was detected during germination/seedling growth $(r=0.12, p=0.059)$, when the relationship between DON content in harvested oats and daily number of hours with vpd $\leq 0.34 \mathrm{kPa}$ combined with $T \geq 10^{\circ} \mathrm{C}$ was considered. Positive correlations between DON content in harvested oats and daily number of hours with moist and moderate to warm weather (vpd $\leq 0.34 \mathrm{kPa}$ and $T \geq 10^{\circ} \mathrm{C}$ ) were also found from inflorescence emergence to milk development with the maximum value detected during heading/flowering $(r=0.37, p<0.001)$. No significant effects were detected in the late milk or dough development stages, while a significant negative correlation was found during ripening $(r=-0.24, p<0.001)$. By considering the relationship between DON and daily number of hours with vpd $\leq 0.34 \mathrm{kPa}$, combined with $T \geq 15^{\circ} \mathrm{C}$, the negative effect observed at ripening was strengthened $(r=-0.35$, $p<0.001$ ), and a negative correlation at late milk $(r=-0.12, p=0.045)$ and dough development $(r=-0.13, p=0.037)$ appeared.

The relationship between DON content in harvested oats and daily number of hours with moist and cool weather (vpd $\leq 0.34 \mathrm{kPa}$ and $T<10{ }^{\circ} \mathrm{C}$ ) is presented in Fig. 2h. Negative correlations were found both at germination/seedling growth $(r=-0.14, p=0.030)$ and tillering $(r=-0.17, p=0.006)$. By contrast, no correlations were detected between DON content and daily number of hours with $\mathrm{vpd} \leq 0.34 \mathrm{kPa}$ and $T<10{ }^{\circ} \mathrm{C}$ at heading/flowering, while positive correlations were found from milk development onwards, with the highest correlations observed during dough development $(r=0.38, p<0.001)$ and ripening $(r=0.39$, $p<0.001)$.

\section{Part 3: prediction models for risk of DON}

Two mathematical models were developed to predict the risk of DON contamination in oat grains. One model included weather summarisations from sowing to the end of inflorescence emergence (forecasting system for fungicide treatment) and the second model comprised weather summarizations in the period from sowing to harvest (prognosis system for the authorities and industry). Both models were developed and evaluated using discriminant analysis with stepwise selection and leaveone-out cross validation, considering all weather summarisations with a significant $(p<0.05)$ effect on DON accumulation, and with less correlation to each other than $r=0.9$ (Table S1).

\section{Forecasting system for fungicide treatment}

In the development of a forecasting system for fungicide treatment, a total of 48 weather summarisations (Table S1) were evaluated with stepwise selection and leave one out cross validation in the discriminant analysis. The final model, consisted of nine weather summarisations and is given in Eq. (2).

$$
\begin{aligned}
M 1= & -4.11-0.49 a_{1}+0.27 a_{2}-0.05 b_{1}+0.32 b_{2} \\
& +0.44 b_{3}+0.92 d_{1} \\
& +0.59 e_{1}-1.38 e_{2}-0.27 e_{3}
\end{aligned}
$$

The model predicts risk of DON exceeding $1000 \mu \mathrm{g} \mathrm{kg}^{-1}$ if the model output M1 is greater than zero. The model variables $a$, are weather summarisations during the phenological window germination/seedling growth, with respectively being the daily number of hours with $P>0.2 \mathrm{~mm}\left(a_{1}\right)$ and daily number of hours with $\mathrm{T}$ in $\left[10,15{ }^{\circ} \mathrm{C}\right.$ and $P \leq 0.2 \mathrm{~mm}\left(a_{2}\right)$. Furthermore, the model variables $b$, are weather summarisations during the phenological window tillering, with respectively being the average daily RH $\left(b_{1}\right)$, the daily number of hours with $T<15{ }^{\circ} \mathrm{C}$ and $P \leq 0.2 \mathrm{~mm}\left(b_{2}\right)$ and daily number of hours with $T \geq 20^{\circ} \mathrm{C}$ and vpd $>0.51 \mathrm{kPa}\left(b_{3}\right)$. The model variable $d_{1}$ is the daily number of hours with T in $\left[15,30^{\circ} \mathrm{C}\right.$ and $P>0.2 \mathrm{~mm}$ during booting, while the model variable $e$, are weather summarisations during the phenological window inflorescence emergence: the daily number of hours with $T \geq 12^{\circ} \mathrm{C}$ and $P>0.2 \mathrm{~mm}\left(e_{1}\right)$, the daily number of hours with $T<10^{\circ} \mathrm{C}$ and $P>0.2 \mathrm{~mm}$ $\left(e_{2}\right)$, and the daily number of hours with $\mathrm{T}$ in $\left[10,15{ }^{\circ} \mathrm{C}\right.$ and $\mathrm{vpd}<0.17 \mathrm{kPa}\left(e_{3}\right)$.

From the leave-one-out cross validation, the model correctly estimated $76 \%$ of the observations to higher than $1000 \mu \mathrm{g} \mathrm{kg}^{-1} \mathrm{DON}$ while $79 \%$ was correctly estimated to less than $1000 \mu \mathrm{g} \mathrm{kg}^{-1}$ DON. Thus, $24 \%$ of the observations were incorrectly estimated to less than $1000 \mu \mathrm{g} \mathrm{kg}^{-1} \mathrm{DON}$ and $21 \%$ were incorrectly estimated to higher than $1000 \mu \mathrm{g} \mathrm{kg}^{-1} \mathrm{DON}$.

The model generally predicted increased risk of DON with dry conditions during germination/seedling 
growth and tillering, and with warm $\left(T>12^{\circ} \mathrm{C}\right.$, around/ warmer than normal for that period) and wet conditions during booting and inflorescence emergence (Fig. 3). Simultaneously, the model predicted decreased risk of DON with moist and wet conditions during germination/seedling growth and tillering and with cool $\left(T<10{ }^{\circ} \mathrm{C}\right.$, cooler than normal for that period) and moist/wet conditions during inflorescence emergence.

Prognosis system for identification of oat grain lots with DON levels exceeding acceptable limits

In the construction of a prognosis system for authorities and industry, a total of 76 weather summarisations (Table S1) were evaluated with stepwise selection in the discriminant analysis and leave one out cross validation. The final model consisted of eight weather summarisations and is given in Eq. (3).

$$
\begin{aligned}
M 2= & -5.33+0.27 b_{3}+0.49 b_{4}+0.31 e_{4} \\
& +0.27 f_{1}+9.83 i_{1}-0.54 i_{2}-0.42 i_{3}-0.23 j_{1}
\end{aligned}
$$

The model predicts risk of DON if the model output $M 2$ is greater than zero. The model variable $b_{3}$ is as described in Eq. 2, while the model variable $b_{4}$ is the daily number of hours with $T<15^{\circ} \mathrm{C}$ and vpd $>0.17 \mathrm{kPa}$ during tillering. The model variable $e_{4}$ is the daily number of hours with $\mathrm{T}$ in $\left[15,20{ }^{\circ} \mathrm{C}\right.$ and vpd $<0.51 \mathrm{kPa}$ during inflorescence emergence and $f_{l}$ is the daily number of hours with $T \geq 12{ }^{\circ} \mathrm{C}$ and vpd $<0.51 \mathrm{kPa}$ during heading/flowering, The model variables $i$, are weather summarisations during the phenological window of dough development with respectively average daily $\operatorname{vpd}\left(i_{1}\right)$, daily number of hours with $T \geq 20{ }^{\circ} \mathrm{C}$ and vpd $>0.17 \mathrm{kPa}\left(i_{2}\right)$ and daily number of hours with $T \geq 15^{\circ} \mathrm{C}$ and vpd $>0.34 \mathrm{kPa}\left(i_{3}\right)$. Finally, the model variable $j_{1}$ is the daily number of hours with $T<15^{\circ} \mathrm{C}$ and $\mathrm{vpd}>0.17 \mathrm{kPa}$ during ripening.

From the leave-one-out cross validation, the model correctly estimated $84 \%$ of the observations to higher than $1000 \mu \mathrm{g} \mathrm{kg}^{-1} \mathrm{DON}$ while $79 \%$ was correctly estimated to less than $1000 \mathrm{\mu g} \mathrm{kg}^{-1} \mathrm{DON}$. Thus, $17 \%$ of the observations were incorrectly estimated to less than $1000 \mu \mathrm{g} \mathrm{kg}^{-1} \mathrm{DON}$ and $21 \%$ were incorrectly estimated to higher than $1000 \mu \mathrm{g} \mathrm{kg}^{-1} \mathrm{DON}$.

This model generally predicted increased risk of DON with dry conditions during tillering and dough development, and with warm $\left(T>12{ }^{\circ} \mathrm{C}\right.$, around/ warmer than normal for that period) and moist conditions during inflorescence emergence and heading/ flowering (Fig. 4). Simultaneously, the model predicted a decreased risk of DON with warm $\left(T>15^{\circ} \mathrm{C}\right.$, warmer than normal for that period) and moist conditions during dough development and with cool $\left(T<15^{\circ} \mathrm{C}\right.$, around/ cooler than normal for that period) and dry conditions during ripening.

\section{Discussion}

The goal of this paper was to identify possible associations between the development of DON in harvested oat grains and weather conditions at specific oat growth stages.

Oat phenology model

The predictive model for phenological development of plant growth, Oat Phenological Model 1, was based on

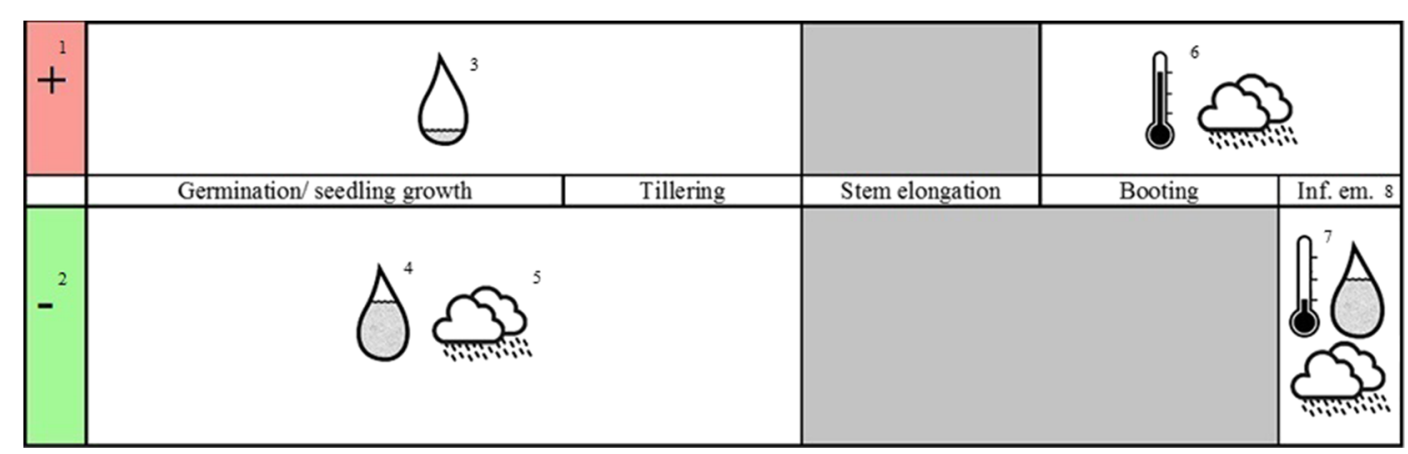

Fig. 3 A visualization of the model predicting DON content in harvested oats for farmers, including weather observations during the different phenological windows from sowing to the end of inflorescence emergence 


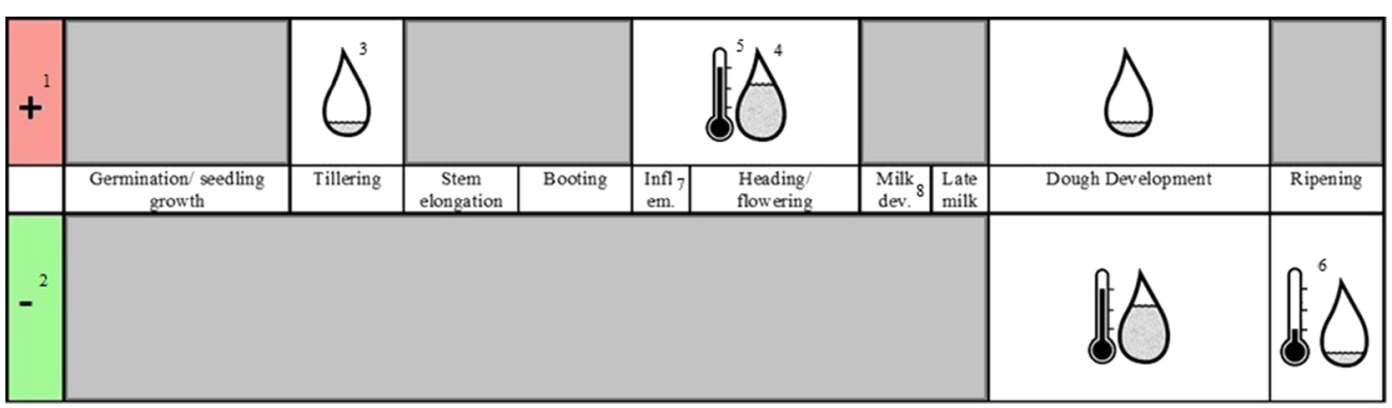

Fig. 4 A visualization of the model predicting DON content in harvested oats for authorities and industry, including weather observations during the different phenological windows from sowing to harvest

the sigmoid Gompertz growth function of degree-day accumulation from sowing, with a base air temperature of $0{ }^{\circ} \mathrm{C}$. In line with our data, Shaykewich (1995) concluded that the phenological developmental rate of most cereal species is a sigmoid rather than a linear function of air temperature. It has the advantage of being simple and asymmetric, which is an advantage compared to the symmetrical logistic curve, since growth is not always symmetrical about the point of inflection.

Our final model for phenological development in oats included only one weather factor, air temperature. This aligns with several other studies that concluded that air temperature is the single most important weather factor for plant development (Sonego et al. 2000; Olesen et al. 2012). The base temperature used in the degree-day accumulation, is the threshold temperature were plant development stops. A base air temperature equal to $0{ }^{\circ} \mathrm{C}$ (Siebert and Ewert 2012) and $5{ }^{\circ} \mathrm{C}$ (Rajala and Peltonen-Sainio 2011; Olesen et al. 2012) are both commonly used for calculations of phenological development in oats. Moisture was not included in our final model, and has previously been shown to be unimportant to the phenological development of spring wheat (Davidson and Campbell 1983). Some studies have included the response of day length or photoperiod in their calculations of phenological development of plants (Wang and Engel 1998; Siebert and Ewert 2012). However, these factors did not improve the prediction ability of Oat Phenological Model 1. The temperature response for wheat, showed optimum temperature for plant growth (Wang and Engel 1998; McMaster et al. 2008), however we found that the use of a weighting function on the air temperatures in the degree-day accumulation (Yan and Hunt 1999) did not improve our model.

The majority of our growth stage observations were recorded at GS 59, which is within the period we defined as heading/flowering, and at GS 87, dough development. A wide variation in the number of days from sowing until GS 59 and GS 87 was found for the oat fields observed in our study. When we plotted phenological growth against degree-days (Oat Phenological Model 1), instead of the number of days from sowing, the observed data on these two specific phenological growth stages were closer with a clearly decreased relative standard deviation. Furthermore, when we estimated the developmental stages based upon the number of days from sowing, we observed an overlap between the two separate phenological phases GS 59 (between 53 and 82 days from sowing) and GS 87 (between 81 and 119 days from sowing), which complicated the use of number of days as a predictor for growth stage. This overlap disappeared when we used Oat Phenological Model 1 to calculate the growth stages of oats based upon degree-days from sowing, and thus it appears this model provided a more definite picture with a clear difference in time between heading/flowering and dough development. Still, substantial variation was found at both phenological phases GS 59 (observed from 647 to 894 degree days from sowing) and GS 87 (observed from 1148 to 1611 degree days from sowing). Some of the variation observed is likely due to the differences in the time from sowing to maturity for the early and late maturing oat varieties included in our study. The variation in the observed degree-days from sowing was higher at the later phenological phase dough development (GS 87) compared to at heading/flowering (GS 59). According to Peltonen-Sainio and Rajala (2007), only the duration of the grain filling period consistently differed between oat varieties, while the duration of vegetative and generative pre-anthesis phases and sub-phases did not. If early and late maturing oat varieties differ in the duration of their grain filling period, it may explain why more variation was detected at GS 87 compared to GS 59 in our model. In this case, a 
more precise model would likely have been constructed if data were grouped according to the maturity of the different varieties included in our phenology model. Additionally, soil type, tillage and measurement errors may also have contributed to the observed variation.

The development of spikelets in oat proceeds from the uppermost terminal spikelet downwards to the base of the panicle, resulting in a longer pollination period compared to wheat (Rajala and Peltonen-Sainio 2011). Our Oat Phenological Model 1 predicted that the heading/ flowering period (GS55-GS69) will last for 15 days with a mean daily air temperature of $16^{\circ} \mathrm{C}$. This is in accordance with findings by Rajala and Peltonen-Sainio (2011) who reported the pollination period (GS61GS69) in oats lasted for ten to eleven days.

Association between DON content and weather conditions at different oat growth stages

The poor relationship we found between number of days from sowing and phenological development in oats, made it impossible to use temporal windows, based on number of days, when quantifying the relationship between environment and DON. The use of phenological windows has not previously been documented, but supports earlier proposed improvements of window pane methodology (Xu et al. 2014). While the window pane methodology (Coakley et al. 1982) quantifies important environmental factors and their starting time, our procedure focused on specific growth stages, and identified the associations between DON content in harvested oat grains and environmental factors within each growth stage. This is in agreement with most mechanistic models for FHB development in wheat (Rossi et al. 2003; Del Ponte et al. 2005) that generally include the dynamics of the host.

Our results indicate that DON contamination in harvested oat grains was influenced by weather conditions during the early phenological growth stages from sowing to the end of tillering, although higher associations were detected during later growth stages. Rainy conditions at early growth stages did not promote DON development in our study, despite the fact that moisture promotes the development of $F$. graminearum perithecia (Pereyra et al. 2004). Decreased F. graminearum on plant debris has been detected in years with high precipitation in early spring (Hofgaard et al. 2016b). Temperature influences the mycelial growth rate of Fusarium species (Brennan et al. 2003), with different optimal growth temperatures for different species. Fusarium graminearum is regarded as the main DON producer in Norwegian oats (Hofgaard et al. 2016a), and warmer temperatures may increase the competitive ability of this species in Norway. Fusarium graminearum has an optimum growth temperature of $25{ }^{\circ} \mathrm{C}$ (Brennan et al. 2003) and thus this species generally dominates in warmer geographical regions. Other species within the FHB complex, such as Microdochium spp., have a lower optimum temperature and are favoured in cooler maritime areas (Maurin et al. 1995). The negative association between DON and cool, rainy conditions during spring identified in our study and in Hofgaard et al. (2016b), may be a result of increased competition in plant residues between $F$. graminearum and other $F u$ sarium species or fungal or bacterial saprophytes that are betted adapted to these weather conditions. Survival of $F$. graminearum on plant debris is inversely related to decomposition rate (Pereyra et al. 2004). Over time, $F$. graminearum colonization of debris decreases whereas the relative prevalence of other Fusarium species increases (Pereyra et al. 2004). In a study of Fusarium colonization on wheat debris, the greatest rate of decline in F. graminearum colonization was detected during early spring (Pereyra et al. 2004), which may indicate that spring is a period of change in the colonization of debris by fungal species.

The amount of fungal inoculum in a field, whether as spores or as mycelium capable of infecting plants, depends on the quantity of infested residues (Dill-Macky and Jones 2000; Pereyra et al. 2004). Soil moisture and soil temperature affect the decomposition rate of crop debris and subsequently the survival of plant pathogens in crop debris (Pereyra et al. 2004; Hofgaard et al. 2016b). We detected increased DON accumulation in oat grains from fields with dry and moderate to warm weather during the early phenological phases, which may be the result of better survival of $F$. graminearum on residues in these conditions. Similar associations between DON accumulation and warm weather during early phenological growth stages have been recorded in wheat (Klem et al. 2007; Landschoot et al. 2012b).

Minor associations were detected between DON content and weather conditions during stem elongation and booting. These low associations might be due to high uncertainty in the prediction of the growth stages resulting from the few observed data points at these phenological growth stages used in the development of Oat Phenological Model 1. 
In our Spearman rank correlation study, DON accumulation was highly influenced by weather conditions during inflorescence emergence and heading/flowering. DON accumulation was enhanced in oat grains from fields with wet/moist weather around flowering and from fields with wet/moist weather in combination with high air temperatures around flowering, which correspond to the general consensus of the weather conditions that promote DON accumulation in wheat (Hooker et al. 2002; Klem et al. 2007; Landschoot et al. 2012b).

Cereal plants are most susceptible to infection by F. graminearum at flowering (Anderson 1948), and in order to achieve successful infection, inoculum must be available and favourable weather conditions prevail. Both initial infection (Anderson 1948; McMullen et al. 2012) and FHB development ( Xu 2003; Kriss et al. 2010) are favoured by warm/moist conditions, and thus the increased DON accumulation with warm and wet/ moist conditions found in our study are as expected.

While DON content was greater in oat grains harvested from fields with warm and wet/moist weather during flowering, our study detected a negative association between DON accumulation and air temperatures. A similar negative association between DON content in harvested grain and high air temperatures for the five days after flowering has been reported in wheat (Klem et al. 2007). During periods with high air temperatures and limited precipitation, the water capacity of the air likely increases, resulting in lower moisture availability, which reduces the ability for the fungus to sporulate, disperse and infect oat plants. In addition, high air temperatures may accelerate plant development and reduce the length of the flowering period, thereby reducing the risk of $F$. graminearum infection and subsequent DON accumulation. Some FHB models have avoided using air temperature as an explanatory variable alone (De Wolf et al. 2003; Shah et al. 2013). Crop debris is recognized as a source of F. graminearum inoculum (Pereyra et al. 2004). Rainfall is important for conidial dispersal (Xu 2003; Paul et al. 2004), thus the positive impact of mean daily precipitation found in our study confirms the importance of spread of the splash dispersed macroconidia (Paul et al. 2004; Skelsey and Newton 2015) when the plant is most susceptible to infection (Tekle et al. 2012). Rain increases the moisture of crop debris (Manstretta and Rossi 2015) and thus also favours the development of perithecia and maturation of ascospores (Manstretta and Rossi 2016).
Weather conditions during the post-flowering period, from milk development to harvest, had a major impact on DON accumulation in our study, in agreement with findings on winter wheat (Cowger et al. 2009). We detected an increased DON content in oat grains harvested from fields with cool and moist weather during this period. The importance of moisture post-flowering has also been reported alone (Cowger et al. 2009; Andersen et al. 2015; Kharbikar et al. 2015) and in combination with warm weather (Franz et al. 2009). No association was detected between the DON accumulation and rain during late milk and dough development in our study, although a positive association was detected between DON and precipitation during milk development. Warm and moist weather after flowering has previously been associated with increased DON accumulation in winter wheat (Franz et al. 2009), whereas in our data DON accumulation in oat grain was associated with cool and moist weather in the post-flowering period. In Norway, rainy days are usually associated with low air temperatures and this might be the reason for the association we observed between DON contamination and low temperatures.

We detected a negative association between DON accumulation and rain during ripening in our study, with the highest correlation detected at high temperatures. This is in agreement with the study of Culler et al. (2007), who reported a lower DON content in wheat from fields/plots treated with extended periods of irrigation from flowering to harvest when compared to control. Leaching of DON from spikes may occur at high rainfall (Cowger et al. 2009; Gautam and DillMacky 2012), and so precipitation during grain ripening in oat may similarly impact DON accumulation in oat.

Summarizing comments on the relationship between weather conditions and DON content

The association between weather conditions during plant development and DON accumulation in harvested oat grains clearly differed between the phenological windows examined in our study. Dry and warm conditions during early growth stages for oats were associated with increased DON accumulation, whereas low air temperatures and precipitation in this period were associated with reduced DON. We speculate this reflects the competitive ability of $F$. graminearum being influenced by temperature and moisture. Furthermore, wet/moist weather around flowering was associated with increased 
DON accumulation. This may reflect the importance of wet/moist conditions for the build-up of $F$. graminearum inoculum and successful infection of the oat panicle. Weather conditions from heading/flowering to harvest gave the highest correlations with DON accumulation in our study, while weather conditions during early growth stages were less associated with DON accumulation. This is in agreement with most studies of FHB in wheat (Kriss et al. 2010; Shah et al. 2013). Associations between weather conditions during plant development (pre-, around and post-flowering) and DON accumulation in grains are often evaluated in models developed to examine DON in wheat (Hooker et al. 2002; De Wolf et al. 2003; Klem et al. 2007). In prediction models developed for F. graminearum and DON in wheat, only weather conditions pre- and around flowering are included, while weather conditions close to harvest are not (Hooker et al. 2002; De Wolf et al. 2003; Klem et al. 2007), except for the dynamic simulation model for the risk for Fusarium head blight in wheat (Rossi et al. 2003). According to the study by Giroux et al. (2016) a model developed by De Wolf et al. (2003) was best among the nine models evaluated in order to predict DON levels in wheat in Quebec (Canada). Their model only considered weather conditions during a 10-day window from flowering.

\section{Prediction models for risk of DON}

Two empirical models were developed in our study, the first model (M1) included only pre-flowering weather conditions (from sowing to the end of inflorescence emergence) and the second model (M2) included weather conditions from sowing until harvest. Both models predicted the risk of DON adequately, with $79 \%$ of the observations correctly estimated when DON was less than $1000 \mu \mathrm{g} \mathrm{kg}^{-1}$. The second model (M2) was better able to predict DON values above $1000 \mu \mathrm{g} \mathrm{kg}^{-1}$, with $84 \%$ of the observations correctly estimated compared to $76 \%$ for M1.

According to both models, DON accumulation increases with dry conditions during early stages (M1: germination/seedling growth, M1 and M2: tillering), independently of air temperature, and with warm and moist/wet weather conditions before flowering (M1: booting, M1 and M2: inflorescence emergence). Both these effects were strengthened when more weather variables were included in M1. Increased DON accumulation has been associated with warm and moist/wet conditions before flowering in several studies (Hooker et al. 2002; De Wolf et al. 2003; Klem et al. 2007; Giroux et al. 2016). Weather conditions during heading/flowering and post-flowering were additionally included in M2. In line with the literature (Hooker et al. 2002; De Wolf et al. 2003; Klem et al. 2007; Giroux et al. 2016), increased DON accumulation was associated with warm and moist conditions during heading/ flowering. Conversely, warm and moist conditions during dough development were associated with decreased DON accumulation in our study. During ripening, decreased DON accumulation was associated with cool and dry weather.

Both models developed in this study rely on predicted oat growth stages. The study by Giroux et al. (2016), evaluated nine models to predict DON in wheat, using both predicted and observed phenological stages of the host plant. The precision of the model was lower using predicted growth stages compared to those observed. Thus, an improvement of our models may be achieved by using observed growth stages.

Our study emphasizes that the weather conditions close to harvest have a notable impact on DON accumulation in oat grains. Our model was improved by including weather variables at this stage of crop development. Although not examined in our study, it is evident that agronomic factors, including the type of tillage operation (Hofgaard et al. 2016b), previous crop (DillMacky and Jones 2000) and oat variety (Lillemo et al. 2014), substantially influence the inoculum potential and dispersal of $F$. graminearum, and the susceptibility of oat crop grown.

Oat is a commonly grown crop in temperate regions, and high DON concentrations in oats have been reported in Norway (Hofgaard et al. 2016a), Sweden (Fredlund et al. 2013) and Finland (Nathanail et al. 2015). In addition, DON is also detected in oats from Switzerland (Schirdewahn et al. 2016), Canada (Tamburic-Ilincic 2010) and the U.K. (Edwards 2009). The models developed in this study to predict the risk of elevated DONlevels in spring oats, were developed and validated for Norwegian weather conditions only. These models may as well be useful in other regions where spring oat is grown, although they would need to be validated in these regions. Oats may be infected with a range of mycotoxin-producing Fusarium species. High levels of the mycotoxins HT-2 and T-2 produced by F. langsethiae have been monitored in U.K. and Norwegian oats (Edwards 2007; Hofgaard et al. 2016a). However, the 
relationship between weather and accumulation of HT-2 and $\mathrm{T}-2$, is reported to differ greatly to those observed to correlate well with DON accumulation (Xu et al. 2014), and no positive association has been detected between the concentration of HT-2 and T-2 with DON, or between the species that produce HT-2 and T-2 in oats (Hofgaard et al. 2016a; Fredlund et al. 2013; Edwards 2009). Consequently, the models developed in this study will not be useful to predict the risk of elevated levels of HT-2 and T-2 in oat.

\section{Conclusions}

This study identifies important associations between DON content in oat grains and weather conditions during different predicted growth stages of the host plant. Warm, rainy and humid weather during and around flowering was associated with an increased risk of DON accumulation in oat grains, as were dry periods during germination/seedling growth and tillering. Prior to harvest, warm and humid weather conditions, followed by cool and dry conditions, was associated with decreased risk of DON accumulation. DON contamination was most clearly associated with the weather conditions around flowering and close to harvest. Still, a prediction model for fungicide treatment, including only pre-flowering weather conditions, adequately predicted the risk of DON contamination in oat grain. The prediction model was improved when weather conditions from sowing until harvest were included. Our data show that adequate predictions of the risk of DON in oat grains at harvest can be achieved, based upon weather data observed during the growing season, which is in contrast to a previous study where no clear associations were identified between weather and DON in oat grains. Existing prediction models for DON in wheat emphasize weather conditions around flowering, however, our study also shows that weather conditions at early growth stages, as well as those close to harvest, should be considered in order to achieve better predictions on DON accumulation in oat grains. Despite being developed and validated for Norwegian weather conditions only, our prediction models may also be useful in other regions where spring oat is grown. However separate models must be developed to predict the risk of HT-2 and T-2, because these mycotoxins are produced by Fusarium species that are not associated with the same weather conditions as the DON producers.
Acknowledgements We acknowledge all farmers who supplied grain samples. We also thank the workers at the different elevators and at the Norwegian Agricultural Extension Service, who have coordinated and supplied grain samples. Thanks to the staff at KIMEN Seed Laboratory for cleaning and milling the grain. This work was funded by: the Research Council of Norway (research grant 173277/I10 and 199412/I99), the Foundation for Research Levy on Agricultural Products/Agricultural Agreement Research Fund, Felleskjøpet Agri, Nordisk Korn/Fiskå Mølle, Norgesfôr/ Strand Unikorn, Bayer Crop Science, Felleskjøpet Rogaland og Agder, Norgesmøllene, Braskereidfoss Kornsilo, Flisa Mølle og Kornsilo, Norkorn, Lantmännen Cerealia and NIBIO. Field data for the development of the oat phenology model were obtained from The Nordic Field Trial System.

Open Access This article is distributed under the terms of the Creative Commons Attribution 4.0 International License (http:// creativecommons.org/licenses/by/4.0/), which permits unrestricted use, distribution, and reproduction in any medium, provided you give appropriate credit to the original author(s) and the source, provide a link to the Creative Commons license, and indicate if changes were made.

\section{References}

Aamot, H. U., Hofgaard, I. S., Brodal, G., Elen, O., Jestoi, M., \& Klemsdal, S. S. (2012). Evaluation of rapid test kits for quantification of deoxynivalenol in naturally contamined oats and wheat. World Mycotoxin Journal, 5(4), 339-350.

Agrometeorology Norway (2016). lmt.nibio.no.

Andersen, K. F., Madden, L. V., \& Paul, P. A. (2015). Fusarium head blight development and deoxynivalenol accumulation in wheat as influenced by post-anthesis moisture patterns. Phytopathology, 105(2), 210-219.

Anderson, A. L. (1948). The development of Gibrella zeae headblight of wheat. Phytopathology, 38, 599-611.

Åssveen, M., Tangsveen, J., \& Weiseth, L. (2015). Sorter og sortsprøving 2014. Bioforsk FOKUS, 10(1), 34-66.

Batschelet, E. (1976). Introduction to mathematics for life scientists. New York: Springer.

Brennan, J. M., Fagan, B., van Maanen, A., Cooke, B. M., \& Doohan, F. M. (2003). Studies on in vitro growth and pathogenicity of European fusarium fungi. European Journal of Plant Pathology, 109(6), 577-587.

Coakley, S. M., Boyd, W. S., \& Line, R. F. (1982). Statistical models for predicting strip rust on winter wheat in the Pacific northwest. Phytopathology, 72(12), 1539-1542.

Cowger, C., Patton-Özkurt, J., Brown-Guedira, G., \& Perugini, L. (2009). Post-anthesis moisture increased fusarium head blight and deoxynivalenol levels in North Carolina winter wheat. Phytopathology, 99(4), 320-327.

Culler, M. D., Miller-Garvin, J. E., \& Dill-Macky, R. (2007). Effect of extended irrigation and host resistance on deoxynivalenol accumulation in Fusarium-infected wheat. Plant Disease, 91(11), 1464-1472. 
Davidson, H. R., \& Campbell, C. A. (1983). The effect of temperature, moisture and nitrogen on the rate of development of spring wheat as measured by degree days. Canadian Journal of Plant Science, 63(4), 833-846.

De Wolf, E. D., Madden, L. V., \& Lipps, P. E. (2003). Risk assessment models for wheat fusarium head blight epidemics based on within-season weather data. Phytopathology, 93(4), 428-435.

Del Ponte, E. M., Fernandes, J. M. C., \& Pavan, W. (2005). A risk infection simulation model for fusarium head blight of wheat. Fitopatologia Brasileira, 30, 634-642.

Dill-Macky, R., \& Jones, R. K. (2000). The effect of previous crop residues and tillage on fusarium head blight of wheat. Plant Disease, 84(1), 71-76.

Edwards, S. (2007). Investigation of Fusarium mycotoxins in UK barley and oat production. HGCA-AHDB Proj. Rep. No. 500. Stoneleigh, UK.

Edwards, S. G. (2009). Fusarium mycotoxin content in UK organic and conventional oats. Food additives and Contaminants: Part A, 26(7), 1063-1069.

European Commission (2003). Collection of occurrence of Fusarium toxins in food and assessment of dietary intake by the population of EU Member States. Bryssel, Belgium.

Franz, E., Booij, K., \& van der Fels-Klerx, I. (2009). Prediction of deoxynivalenol content in Dutch winter wheat. Journal of Food Protection, 72(10), 2170-2177.

Fredlund, E., Gidlund, A., Sulyok, M., Börjesson, T., Krska, R., Olsen, M., \& Lindblad, M. (2013). Deoxynivalenol and other selected Fusarium toxins in Swedish oats - Occurence and correlation to specific Fusarium species. International Journal of Food Microbiology, 167, 276-283.

Gautam, P., \& Dill-Macky, R. (2012). Free water can leach mycotoxins from fusarium-infected wheat heads. Journal of Phytopathology, 160(9), 484-490.

Giroux, M. E., Bourgeois, G., Dion, Y., Rioux, S., Pageau, D., Zoghlami, S., Parent, C., Vachon, E., \& Vanasse, A. (2016). Evaluation of forecasting models for fusarium head blight of wheat under growing conditions of Quebec, Canada. Plant Disease, 100(6), 1192-1201.

Goff, J. A., Gratch, S. (1946). Low-pressure properties of water from -160 to 212 F. In Transactions of the American society of heating and ventilating engineers. New York: American Society of Heating and Ventilating Engineers.

Gourdain, E., Piraux, F., \& Barrier-Guillot, B. (2011). A model combining agronomic and weather factors to predict occuence of deoxynivalenol in durum wheat kernels. World Mycotoxin Journal, 4(2), 129-139.

Hastie, T., Tibshirani, R., \& Friedman, J. (2001). The elements of statistical learning. Data mining, inference and prediction. Canada: Springer.

Hofgaard, I. S., Aamot, H. U., Torp, T., Jestoi, M., Lattanzio, V. M. T., Klemsdal, S. S., Waalwijk, C., Van der Lee, T., \& Brodal, G. (2016a). Associations between Fusarium species and mycotoxins in oats and spring wheat from farmers' fields in Norway over a six-year perio. World Mycotoxin Journal, 9(3), 365-378.

Hofgaard, I. S., Seehusen, T., Aamot, H. U., Riley, H., Razzaghian, J., Le, V. H., Hjelkrem, A. G. R., Dill-Macky, R., \& Brodal, G. (2016b). Inoculum potential of Fusarium spp. relates to tillage and straw management in Norwegian fields of spring oats. Frontiers in Microbiology, 7, 556.
Hooker, D. C., Schaafsma, A. W., \& Tamburic-Ilincic, L. (2002). Using weather variables pre- and post-heading to predict deoxynivalenol content in winter wheat. Plant Disease, 86(6), 611-619.

Kharbikar, I., Dickin, E., \& Edwards, S. G. (2015). Impact of postanthesis rainfall, fungicide and harvesting time on the concentration of deoxynivalenol and zeralenole in wheat. Food Additives \& Contaminants: Part A, 32(12), 2075-2085.

Klem, K., Váòová, M., Hajšlová, J., Lancová, K., \& Sehnalová, M. (2007). A naural network model for prediction of deoxynivalenol content in wheat grain based on weather data and preceding crop. Plant Soil Environment, 53(10), 421-429.

Kokkonen, M. K., \& Jestoi, M. N. (2009). A multi-compound LCMS/MS method for the screening of mycotoxins in grains. Food Analytical Methods, 2(2), 128-140.

Kriss, A. B., Paul, P. A., \& Madden, L. V. (2010). Relationship between yearly fluctuations in fusarium head blight intensity and environmental variables: a window-pane analysis. Phytopathology, 100(8), 784-797.

Kriss, A. B., Paul, P. A., Xu, X., Nicholson, P., Doohan, F. M., Hornok, L., Rietini, A., Edwards, S. G., \& Madden, L. V. (2012). Quantification of the relationship between the environment and fusarium head blight, fusarium pathogen density, and mycotoxins in winter wheat in Europe. European Journal of Plant Pathology, 133(4), 975-993.

Lancashire, P.D., Bleiholder, H., Van Den Boom, T., Langelüddeke, P., Stauss, R., Weber, E., Witzenberger, A. (1991). A uniform decimal code for growth stages of crops and weeds. Annals of Applied Biology, 119(3).

Landschoot, S., Waegeman, W., Audenaert, K., Vandepitte, J., Haesaert, G., \& De Baets, B. (2012a). Toward a reliable evaluation of forecasting Systems for Plant Diseases: a case study using fusarium head blight of wheat. Plant Disease, 96(6), 889-896.

Landschoot, S., Waegeman, W., Audenaert, K., Vendepitte, J., Baetens, J., De Baets, B., \& Haesaert, G. (2012b). An empirical analysis of explanatory variables affecting fusarium head blight infection and deoxynivalenol content in wheat. Journal of Plant Pathology, 94(1), 135-147.

Lillemo, M., Skinnes, H., Buraas, Å., Reitan, T., Bergersen, S., \& Diseth, J. A. (2014). Choice of resistent cultivars as means to deduce the risk of mycotoxin in wheat, barley and oats - how big are varietal differences, and what are the characteristics of resistens cultivars? NJF Report, 10(9), 10.

Lindblad, M., Börjesson, T., Hietaniemi, V., \& Elen, O. (2011). Statistical analysis of agronomical factors and weather conditions influencing deoxynivalenol levels in oats in Scandinavia. Food Additives \& Contaminants: Part A, 29(10), 1566-1571.

Manstretta, V., \& Rossi, V. (2015). Modelling the effect of weather on moisture fluctuations in maize stalk residues, an important inoculum source for plant diseases. Agricultural and Forest Meteorology, 207, 83-93.

Manstretta, V., \& Rossi, V. (2016). Effects of temperature and moisture on development of Fusarium graminearum perithecia in maize stalk residues. Applied and Environmental Microbiology, 82(1), 184-191.

Maurin, N., Saur, L., \& Capron, G. (1995). Stem and head reaction of winter wheat cultivars to artificial inoculation by 
Microdochium nivale under controlled environment and field conditions. Euphytica, 92(3), 359-366.

McMaster, G. S., White, J. W., Hunt, L. A., Jamieson, P. D., Dhillon, S. S., \& Ortiz-Monasterio, J. I. (2008). Simulating the influence of Vernalization, photoperiod and optimum temperature on wheat developmental rates. Annals of Botany, 102(4), 561-569.

McMullen, M., Bergstrom, G., De Wolf, E., Dill-Macky, R., Hershman, D., Shaner, G., \& Van Sanford, D. (2012). A unified effort to fight an enemy of wheat and barley: fusarium head blight. Plant Disease, 96(12), 1712-1728.

Montgomery, D. C., Peck, E. A., \& Vining, C. G. (2001). Introduction to linear regression analysis. New York: Wiley Interscience, Third edition.

Nathanail, A. V., Syvähoko, J., Malachová, A., Jestoi, M., Varga, E., Michlmayr, H., Adam, G., Sieviläinen, E., Berthiller, F., \& Peltonen, K. (2015). Simultaneous determination of major type a and $\mathrm{B}$ trichothecenes, zeralenone and certain modified metabolotes in Finnish cereal grains with novel liquid chromatogrphy-tandem mass spectrometric method. Analytical and Bioanalytical Chemistry, 407(16), 4745-4755.

Norwegian Scientific Commitee for Food Safety. (2013). Risk assessment of mycotoxins in cereal grain in Norway. Opinion of the Scienific Steering Committe of the Norwegian Scientific Commitee for Food Safety (pp. 287). Oslo, Norway. Available at http://www.vkm. no/dav/eee04d10c4.pdf.

Olesen, J. E., Børgesen, C. D., Elsgaard, L., Palosuo, T., Rötter, R. P., Skjelvåg, A. O., Peltonen-Sainio, P., Börjesson, T., Trnka, M., Ewert, F., Siebert, S., Brisson, N., Eitzinger, J., Van Asselt, E. D., \& Oberforster, M. (2012). Changes in time of sowing, flowering and maturity of cereals in Europe under climate change. Food Additives \& Contaminants: Part A, 29(10), 1527-1542.

Olseth, J.A., \& Skartveit, A. (1985). Strålingshåndboka. Det norske meteorologiske institutt, (6).

Paul, P. A., El-Allaf, S. M., Lipps, P. E., \& Madden, L. V. (2004). Rain splash dispersal of Gibberella zeae within wheat canopies in Ohio. Phytopathology, 94(12), 1342-1349.

Peltonen-Sainio, P., \& Rajala, A. (2007). Duration of vegetative and generative development phases in oat cultivars released since 1921. Field Crops Research, 101(1), 72-79.

Pereyra, S. A., Dill-Macky, R., \& Sims, A. L. (2004). Survival and inoculum production of Gibberella zeae in wheat residue. Plant Disease, 88(7), 724-730.

Perry, R. H., \& Green, D. W. (1997). Perry's Chemical Engineers' Handbook. McGraw-Hill.

Rajala, A., \& Peltonen-Sainio, P. (2011). Pollination dynamics, grain weight and grain cell number within the inflorencence and spikelet in oat and wheat. Agricultural Sciences, 2, 283-290.

Robert, C. P., \& Casella, G. (1999). Monte Carlo statistical methods. New York: Springer-Verlag.

Rossi, V., Giosuè, S., Pattori, E., Spanna, F., \& Del Vecchio, A. (2003). A model estimating the risk of fusarium head blight on wheat. EPPO Bulletin, 33(3), 421-425.
Rougier, J. (2007). Probabilistic inference for future climate using an ensemble of climate model evaluations. Climatic Change, 81(3-4), 247-264.

Saarikko, R. A., \& Carter, T. R. (1996). Phenological development in spring cereals: response to temperature and photoperiod under northern conditions. European Journal of Agronomy, 5(1-2), 59-70.

Schirdewahn, T., Martin, C., Mascher, F., Bucheli, T. D., Bertossa, T. D., Musa, T., \& Vogelsang, S. (2016). Elucidating the cropping factors influencing Fusarium species and mycotoxin occurrence in Swiss oats. Oats 2016: St. Petersburg. oats2016.org/files/present/2/4/5.pdf.

Shah, D. A., Molineros, J. E., Paul, P. A., Willyerd, K. T., Madden, L. V., \& De Wolf, E. D. (2013). Predicting fusarium head blight epidemics with weather-driven pre- and post-anthesis logistic regression models. Phytopathology, 103(9), 906-919.

Shaykewich, C. F. (1995). An appraisal of cereal crop phenology modelling. Canadian Journal of Plant Science, 75(2), 329-341.

Siebert, S., \& Ewert, F. (2012). Spatio-temporal patterns of phenological development in Germany in relation to temperature and day length. Agricultural and Forest Meteorology, 152, 44-57.

Skelsey, P., \& Newton, A. (2015). Future environmental and geographic risks of fusarium head blight of wheat in Scotland. European Journal of Plant Pathology, 142(1), 133-147.

Sonego, M., Moot, D. J., Jamieson, P. D., Martin, R. J., \& Scott, W. R. (2000). Apical development in oats predicted by leaf stage. Field Crops Research, 65(1), 79-86.

Spearman, C. (2010). The proof and measurement of association between two things. International Journal of Epidemiology, 39(5), 1137-1150.

Tamburic-Ilincic, L. (2010). Fusarium species and mycotoxins associated with oat in southwestern Ontario, Canada. Canadian Journal of Plant Science, 90, 211-216.

Tekle, S., Dill-Macky, R., Skinnes, H., Tronsmo, A., \& Bjørnstad, $\AA$. (2012). Infection process of Fusarium graminearum in oats (Avena sativa L.). European Journal of Plant Pathology, 132(3), 431-442.

Wang, E., \& Engel, T. (1998). Simulation of phenological development of wheat crops. Agricultural Systems, 58(1), 1-24.

$\mathrm{Xu}, \mathrm{X}$. (2003). Effects of environmental conditions on the development of fusarium ear blight. European Journal of Plant Pathology, 109(7), 683-689.

Xu, X., Madden, L.V., Edwards, S.G., Doohan, F.M., Moretti, A., Hornok, L., Nicholson, P. (2013). Developing logistic models to relate the accumulation of DON associated with Fusarium head blight to climatic conditions in Europe. European Journal of Plant Pathology, 137(4).

Xu, X., Madden, L. V., \& Edwards, S. G. (2014). Modeling the effects of environmental conditions on HT2 and T2 toxin accumulation in field oat grains. Phytopathology, 104(1), 57-66.

Yan, W., \& Hunt, L. A. (1999). An equation for modelling the temperature response of plants using only the cardinal temperatures. Annals of Botany, 84(5), 607-614. 